\title{
Transparency, Efficiency and the Distribution of Economic Welfare in Pass-Through Investment Trust Games*
}

\author{
Thomas A. Rietz ${ }^{\dagger}$ \\ Roman M. Sheremeta \\ Timothy W. Shields ${ }^{\sharp}$ \\ Vernon L. Smith ${ }^{\S}$
}

December, 2011

\begin{abstract}
We design an experiment to examine welfare and behavior in a multi-level trust game representing a pass through investment in an intermediated market. In a repeated game, an investor invests via an intermediary who lends to a borrower. A pre-experiment one-shot version of the game serves as a baseline and to type each subject. We alter the transparency of exchanges between non-adjacent parties. We find transparency of the exchanges between the investor and intermediary does not significantly affect welfare. However, transparency regarding exchanges between the intermediary and borrower promotes trust on the part of the investor, increasing welfare. Further, this has asymmetric effects: borrowers and intermediaries achieve greater welfare benefits than investors. We discuss implications for what specific aspects of financial market transparency may facilitate more efficiency.
\end{abstract}

JEL Classifications: C72, C91, D72, G14, G21

Keywords: financial intermediation, financial market transparency, pass through securities, multi-level trust games, experiments

\footnotetext{
* The authors would like to thank and dedicate this paper to John Dickhaut who brought us together as researchers, inspired our thinking in this area and worked with us in designing the game studied in this paper. We would also like to thank the Economic Science Institute at Chapman University for funding this research.

${ }^{\dagger}$ Henry B. Tippie College of Business, University of Iowa, Iowa City, Iowa 52242-1000, U.S.A.

* Argyros School of Business and Economics, Chapman University, One University Drive, Orange, CA 92866, U.S.A.

${ }^{\S}$ Economic Science Institute, Chapman University, One University Drive, Orange, CA 92866, U.S.A
} 


\section{Introduction}

Berg, Dickhaut and McCabe (1995) investigate trust and reciprocity in a two-player investment trust game. Since then, the game has been studied extensively. Ostrom and Walker (2005), among others, review the literature and identify that social distance, communication and reputation all affect the degree of trust and reciprocity. The primary focus is on one-to-one trust and reciprocity behavior.

In reality, many situations require multiple levels of trust. For example, when a person invests in a bond fund, he or she trusts the fund manager not to misrepresent the bonds in the fund. The fund manager, in turn, must trust the bond issuers. Alternatively, consider collateralized debt obligations (CDOs). In the home mortgage market, institutional arrangements emerged in which mortgages were originated by one firm (e.g., Country Wide), sold to an investment banker that assembled them into large packages, and issued Mortgage Backed Securities (a kind of CDO) that were in turn sold to investors. Investors trusted the originators to perform due diligence in evaluating the risk of borrowers, and security issuers to provide adequate data trails and loan servicing arrangements. This chain required multiple levels of trust to justify investment. As the recent financial crisis shows, failures at one level can spread through a multi-level system. Further, the challenges recovering show that the breakdown of serial trust relations can have drastic implications.

Financial market crises frequently prompt calls for reform that include greater transparency. For example, in a letter to the G20 on June 16, 2010, President Obama states: "We should support efforts to enhance transparency and increase disclosure by our large financial institutions." He further asks for: "More transparency and disclosure to promote market integrity and reduce market manipulation.” (Obama, 2010). Transparency is often one of the goals of 
regulation ranging from current calls for reform to the Sarbanes-Oxley Act and the Securities and Exchange Act. One of the stated goals of the Securities and Exchange Commission is: "a far more active, efficient, and transparent capital market that facilitates the capital formation so important to our nation's economy." Notice that all of these are aimed at the capital markets, not at retail lending markets. The implicit assumption is that capital market transparency will improve outcomes. However, it is difficult to draw clear conclusions about the effects of transparency alone or at what level transparency matters in naturally occurring environments. Usually, regulation promoting transparency is tied to other reforms and occurs during a time of other changes to the economy (e.g., the Securities and Exchange Act). Here, using a multi-level trust game, we study transparency in a controlled investment/trust environment to isolate its effects. Further, we can isolate transparency in what are effectively two levels: the capital market (between the investor and intermediary) versus the retail lending market (between the intermediary and the borrower).

The conventional two-player trust game is commonly interpreted as a (single level) investment game. An investor (the first player) invests money with a trustee (the second player) who employs it productively and chooses how much, if any, to return to the investor. Because each player is involved in each transaction and, hence, observes the play of all players, the game is completely transparent. Our game extends this to include a financial intermediary, creating a three-player trust game by adding a third player (the intermediary). This allows us to control transparency at different levels by changing whether each player can observe the play of all others or only observe transactions involving the player directly.

\footnotetext{
${ }^{1}$ http://www.sec.gov/about/whatwedo.shtml\#corpfin, accessed 10/27/2010.
} 
In our game, the three players move sequentially. The first player (the investor) initiates the process by sending money (any portion of his endowment) to the second player (the intermediary) with the amount being tripled. One can interpret the tripled amount as the case where the intermediary creates value through the intermediation process (e.g., through pooling investments, diversification and increased liquidity). The intermediary then decides how much of the tripled amount to loan to the third player (the borrower), with the amount being tripled again. This can be interpreted as putting the money to productive resource use. The borrower chooses how much to return to the intermediary who, in turn, chooses how much to return to the investor. This effectively creates an intermediated market, generating gains from specialization and trade from two interactions based on trust and reciprocity.

Our game is repeated, but we use an independent one-shot pre-experiment version to type the behavior of each subject in his or her role and for comparison with the repeated version. In the one-shot setting, we find that transparency has little effect. However, in the repeated setting, transparency of exchanges between the intermediary and borrower (the retail market) to the investor increase efficiency and payoffs to all parties. Transparency of exchanges between the investor and intermediary (the capital market) to the borrower has no significant effect upon efficiency (if anything, the effect is negative). Therefore, it appears that transparency in respect to the borrower and intermediary exchanges matters most. Transparency regarding the exchanges between the other parties does not matter as much. Further, we find that it is the transparency, and not the specific exchanges, that increases welfare. Last, we find that benefits are asymmetric. The borrowers and intermediaries benefit relatively more than the investors from the ability of investors to view the borrower/intermediary transactions. Thus, it is the retail borrower who gains when his or her moves are transparent. 
Some elements of our three-player trust game can be found in the existing literature. First, our three-player trust game is related to the three-player centipede game with a binary choice space (Rapoport et al., 2003; Murphy et al., 2004) and continuous choice space (Sheremeta and Zhang, 2010). Second, multi-level trust has been studied in the evolutionary literature. For example, Greiner and Levati (2005) use a variant of a trust game in order to implement a cyclical network of indirect reciprocity where the first individual may help the second, the second help the third, and so on until the last, who in turn may help the first. As in a two-player trust game, the authors find that pure indirect reciprocity enables mutual trust in the multi-player environment. ${ }^{2}$ Finally, the three-player trust game is related to a 3-person ultimatum game by Buchner et al. (2004). While related to it, none of this research studies a direct, multi-level trust game corresponding to pass-through securities; nor is transparency varied in such games.

\section{Experimental Environment, Design and Procedures}

\subsection{Three-Player Trust Game}

We implement the three-player linear trust game shown in Figure 1. In the first stage, the investor sends some amount, S1, of his 10 experimental dollar endowment to an intermediary. The amount sent triples on the way. Then, the intermediary sends some amount, S2, to a borrower. The amount again triples. The borrower sends back some amount, R3, to the intermediary. Finally, the intermediary sends back an amount, R2, to the investor.

\footnotetext{
${ }^{2}$ There are several other studies in the literature that investigate direct and indirect trust and reciprocity in a twoplayer trust game (Wedekind and Milinski, 2000; Dufwenberg et al., 2001; Guth et al., 2001; Seinen and Schram, 2006). By allowing receivers to reciprocate towards the other donors, Dufwenberg et al. (2001) find that indirect reciprocity induces insignificantly smaller donations than direct reciprocity and that receivers are more rewarding in the case of indirect reciprocity. Guth et al. (2001) find that indirect reward reduces significantly mutual cooperation compared to the direct reward. In the same line of research, Seinen and Schram (2006) and Wedekind and Milinski (2000) provide experimental evidence on indirect reciprocity in a "repeated helping game" developed by Nowak and Sigmund (1998). In this game, donors decide whether or not to provide costly help to the recipients they are matched with, based on information about the recipient's behavior in encounters with third parties.
} 


\subsection{Experimental Design and Procedures}

We design four treatments as given in Table 1 to study how the level of transparency affects trust and reciprocity. In each treatment, the investor is endowed with 10 experimental dollars and the game proceeds according to the rules described here.

In the baseline treatment No-T (stands for "no transparency"), parties can only observe their bilateral interactions, i.e. the investor cannot see the interactions between the intermediary and the borrower, and the borrower cannot see the interactions between the intermediary and the investor. In the Borrower-T treatment, the interactions between the intermediary and the investor are transparent to the borrower. In the Investor- $\mathrm{T}$ treatment, the interactions between the borrower and intermediary are transparent to the investor. Finally, in the Investor-Borrower$\mathrm{T}$ treatment, all parties can see the interactions of all players.

The experiment was conducted at Chapman University at the Economic Science Institute. Subjects were recruited from a standard subject pool consisting primarily of undergraduate students. Subjects interacted with each other anonymously over a local computer network. The experiment was programmed and conducted using z-Tree (Fischbacher, 2007). The computers were placed within individual cubicles in such a way that all subjects could only view their own computer screen.

At the beginning of each session, subjects were given the instructions for the one-shot threeplayer trust game. An experimenter read the instructions aloud while each subject followed along with their own copy of the instructions. ${ }^{3}$ All subjects were randomly assigned to a specific role, designated generically as player 1 , player 2 , or player 3 to avoid (control for) any value-

\footnotetext{
${ }^{3}$ The instructions, available in Appendix I, explain the structure of the game in detail.
} 
laden terminology. Player 1 was endowed with 10 experimental dollars. In the first stage, player 1 made a decision on how much to send to player 2 (any integer between 0 and 10) and how much to keep. Each dollar sent by player 1 was tripled. In the second stage, player 2 made a decision on how much to send to player 3. The amount sent by player 2 was also tripled. In the third stage, player 3 made a decision on how much to return to player 2 and how much to keep. Finally, in the fourth stage, player 2 made a decision on how much to return to player 1 and how much to keep. All subjects were told that player 1, player 2, and player 3 can send some, all, or none of the amount available to them.

After all subjects completed the one-shot experiment, an experimenter announced a second part of the experiment that lasted for 10 periods. No indication of this second part had been given before subjects participated in the first part of the experiment to avoid any potential supergame strategies. Nor had subjects been told that the experiment would end after the first part. In the second part of the experiment, all subjects remained in the same role assignments (i.e., player 1,2 , or 3 ) as in the first part of the experiment. However, they were randomly re-grouped with other subjects who were in different roles to form a completely new three-player group. Subjects stayed in their newly formed groups for all 10 periods of the second part of the experiment. It was common knowledge that the new pairings would last for 10 periods and that the experiment would end at that time. Each period corresponded to the three-player trust game and it proceeded in exactly the same way as the first part of the experiment. This procedure allowed subjects to participate in a single play of the game, without knowledge of a second 10-period repeat play version of the same stage game, as implemented by Burnham et al. (2000) in their trust games. Hence, in one sitting, data are obtained from both single play and repeated play 
versions of the same game. We use the decisions in the one-shot version to type the behavioral playing characteristics of every subject for subsequent analysis. ${ }^{4}$

After completing both parts of the experiment, subjects were paid for the decisions they made in the one-shot three-player trust game in the first part of the experiment. Also, subjects were paid for one randomly selected play of the 10 decision periods in the second part of the experiment. The earnings were paid privately in cash (US dollars) and each experimental session lasted for about 50 minutes. Experimental dollars where converted to US dollars at a rate of 2 experimental dollars to one US dollar. The average experimental earnings, including a \$7 participation fee, were $\$ 23.15$, ranging from a low of $\$ 8$ to a high of $\$ 79$ (out of a maximum possible \$97). No subject participated more than once, and no subject had prior experience with a similar experimental environment.

\section{Results}

\subsection{Efficiency and Payoffs in a One-Shot Trust Game}

Table 2 reports average amounts sent and/or returned by parties and the efficiency in each treatment. Efficiency is measured as the sum of all three payoffs in the group divided by the maximum possible payoff of 90 experimental dollars. Panel A in the top part of Table 2 indicates that treatments have little effect in the one-shot game.

In Table 3, we report regression results that examine the effect of transparency upon efficiency (regression 1) and payoffs (regressions 2-7) in the one-shot game. Payoffs are the amounts earned by each person after all players have sent and/or returned. In each column we

\footnotetext{
${ }^{4}$ Dickhaut et al. (2008) show that subjects often try to build a reputation as trusting and trustworthy types in hope to elicit more reciprocal behavior in subsequent trust game interactions. Therefore, in order to identify treatment effects in the repeated game setting, it is important to elicit the true type of each subject from a one-shot game where there is no opportunity for false reputation buildings.
} 
report the coefficient estimates and robust standard errors. Regressions (2)-(4) and (5)-(7) are estimated using simultaneous equation estimation procedures to control for endogeneity. The independent dummy-variables Investor-T and Borrower-T represent treatment effects. Examining the data from the one-shot three-player trust game, we find no difference in efficiency and no differences in payoffs across treatments.

There are also no apparent differences in distribution of individual decisions across treatments. Table 4 reports the regression results that examine individual player's behavior in the one-shot game. We use simultaneous equation estimation procedures to control for endogeneity. In each column we report the coefficient estimates for the investors' choices (S1), the intermediaries' (S2 and R2), and the borrowers' (R3). There are no significant differences in aggregate behavior of individual player roles across treatments. This leads to our first result:

Result 1: Transparency has no significant effect on efficiency, payoffs and aggregate behavior in a one-shot multi-level trust game.

This negative result suggests that, if regulators expect transparency will significantly alter outcomes in one-shot or infrequent interactions, they may be disappointed in the outcomes. However, many interactions are repeated and our results differ in repeated games.

\subsection{Efficiency and Payoffs in a Repeated Trust Game}

In contrast to the results in the one-shot game, there are substantial differences in behavior across treatments in the repeated game (Panels B, C and D of Table 2). The difference is especially pronounced in the last five periods of the experiment (Panel C of Table 2), where subjects already had some experience of interacting with the same partners in the three-payer trust game. Figure 2, displaying the time series of efficiency in the repeated game, clearly points 
out that differences in efficiencies across treatments come from the latter periods of the experiment. Overall, we find that treatments with investor and full transparency (Investor-T and Investor-Borrower-T) result in higher amounts sent, amounts returned and efficiencies. Players in all roles tend to have higher payoffs. We describe each of these findings one by one in a series of three subsequent results (Result 2 through 4).

Table 5 reports regression results that examine the effect of transparency upon efficiency and payoffs over time for the repeated game. In each column, we report the coefficient estimates and robust standard errors for the player's choices. ${ }^{5}$ In addition to the Investor-T and Borrower-T dummy-variables, we include an inverse period variable (1/Period) to control for learning (i.e., $1 / 2,1 / 3,1 / 4, \ldots, 1 / 11){ }^{6}$ Regressions (2)-(4) and (5)-(7) are estimated using simultaneous equation estimation procedures to control for endogeneity. Also, when estimating regressions in Table 5, we use the corresponding variables from the one-shot game to control for group/individual specific effects (not reported in the table). ${ }^{7}$ Effectively this serves as a fixed effect.

As shown in regression (1) of Table 5, transparency affects efficiency in the repeated game. In particular, giving the investor full transparency about the transactions between the intermediary and borrower significantly increases efficiency. In contrast, giving the borrower full transparency about the investor and intermediary interactions has no significant (if anything,

\footnotetext{
${ }^{5}$ The robust specification allows for heteroskedasticity using Huber-White standard errors. Clustering by group or running panel models with group fixed effects, replicate the treatment effects since each group of subjects only participates in one treatment. However, we used the information from the one-shot game to control for individual effects, which serves as a fixed effect control.

${ }^{6}$ For a robustness check, we have also tried to include the interaction term (Investor-T times Borrower-T). The estimation results are very similar, with the interaction term being insignificant, and are available upon request. In the remainder of the paper we report the results of the estimation without interaction term.

${ }^{7}$ In estimation of specification (1) we use the efficiency from the one-shot game and in specifications (2)-(7) we used the corresponding payoff variable from the one shot game as a fixed effect.
} 
negative) effect on average efficiency. ${ }^{8}$ We have also conducted a robustness check for these results using the Fama and MacBeth (1973) estimation procedure, and confirmed our findings that, ceteris paribus, providing full transparency to the investor significantly increases efficiency while providing full transparency to the borrower decreases efficiency. ${ }^{9}$

Result 2. Providing transparency to the investor (i.e., allowing the investor to see the exchange between the intermediary and the borrower) significantly increases efficiency, while providing transparency to the borrower (i.e., allowing the borrower to see the exchange between the investor and intermediary) has no (if anything, negative) effect on average efficiency.

This suggests that mandated transparency can have some effects in repeated interactions. However, the kind of transparency that seems effective is retail level transparency. When the capital market knows about the interactions between the intermediary and borrower, efficiency improves. Capital market level transparency (when the borrower knows that interactions between the investor in intermediary), has little effect.

Beyond the overall welfare measure, we examine payoffs of each player in regressions (2)(4) of Table 5. The Investor-T dummy-variable is positive for all parties, albeit marginally significant for the borrower. Shown in Panel D of Table 2, payoffs for the investor increase with full transparency (in respect to the investor), increasing 14 percent on average. When the investor had transparency, in the Investor-T and Investor-Borrower-T treatments, the average payoffs for the intermediary increased 21 percent and average payoffs increased 14 percent for the borrower. As a result, everyone benefits from the investor having transparency. In contrast to the investor, when the borrower had full transparency, denoted by the treatment variable

\footnotetext{
${ }^{8}$ A median regression yields very similar results.

${ }^{9}$ First, we ran simple OLS regressions period by period across groups. Then, separately for each coefficient, we conducted a standard t-test using the vector of estimated coefficients from the period by period OLS regressions. For the details of the estimation procedures see Fama and MacBeth (1973). Estimation results are available from authors upon request.
} 
Borrower-T, his payoff did not change significantly (if anything, it decreased). Interestingly, the borrower fared worse in the Borrower-T than in the No-T treatment, where the average payoffs dropped from 18.3 to 13.6 .

Result 3. Providing transparency to the investor increases payoffs to all players, while providing transparency to the borrower does not change payoffs.

Similar to estimation results for payoffs, regressions (4)-(7) in Table 5 report multivariate regression results for the effect of transparency upon each agent's proportion of payoffs (individual payoff as a fraction of the total payoff) over time for the repeated game. The estimation results indicate that giving the investor transparency increases the intermediary's and borrower's proportions of total payoff (see coefficient for Investor-T), and it decreases the investor's proportion of payoff. Thus, while transparency for investors increases payoffs to all parties, the borrowers and intermediaries benefit by relatively more than the investors (who actually have the increased information sets). As before, no significant effect comes for the Borrower-T dummy-variable.

Result 4. Providing transparency to the investor shifts the distribution of payoffs towards intermediaries and borrowers, while providing transparency to the borrower does not change the distribution of payoffs.

Interestingly, the intermediary's and borrower's proportions increase over time, while investor's proportion decreases, indicating significant learning. This suggests that retail level transparency (when the capital market knows the exchanges between the intermediary and borrower) can actually benefit borrowers by making more funds available for lending and shifting overall economic welfare to them at disproportionate rates. We find this particularly 
interesting in the context of the recent financial crisis where consumers and businesses alike complained that they were hurt because lending "dried up."

\subsection{Determinants of Behavior in a Repeated Trust Game}

The gains from exchange, and hence payoffs and efficiency, are driven by the (multiplied) amounts sent, not the amounts returned. So in order to generate economic surplus, transparency has to affect the amounts sent by the investor and intermediary; while the amounts returned by the borrower and intermediary distribute the surplus and provide the reciprocity needed to encourage future efficiency through future amounts sent. To measure these effects, we examine the individual behavior of the players and the determinants that influence such behavior.

Table 6 reports the regression results that examine behavior over time (periods 2-10) in the ten-period repeated game. We use simultaneous equation estimation procedures to control for endogeneity. In each column we report the coefficient estimates and robust standard errors for the players' choices. In addition to the variables Investor-T, Borrower-T and Inverse Period, we include the independent variable IType, which is the amount sent or returned in the preexperiment one-shot game. While the investor and borrower have a singular value for IType, the intermediary has one representing the amount sent to the borrower (used in regression 2) and another representing the amount sent back to the investor (used in regression 4). In this procedure, we are combining and extending techniques developed in two previous papers. Rigdon et al. (2007) identified the IType of each subject in an extensive form trust game in the first period of a twenty period repeated game, and found this variable highly significant in explaining subsequent behavior in the different treatment conditions they studied. By following Burnham et al. (2000) in observing decisions in a pre-experiment single play version, followed 
by a repeat play version, we are able to measure IType before subjects know they are going to participate in a repeated version of the same game. ${ }^{10}$ Thus, we test whether this independent IType measure persists as a predictive procedure for subsequent subject behavior in a repeated version of the same stage game.

In addition, we include independent variables representing the observable choices in the current period: S1, S2, R3, and S1Vis which is S1 when visible to the borrower. Also we include variables representing the prior period's observable choices: LagS1, LagS2, LagR3, LagR2, and LagS1Vis, LagS2Vis, LagR3Vis and LagR2Vis which are last period's choices when observable to the appropriate player.

As per the regressions (1)-(4) in Table 6, note the dummy-variable Investor-T is only significant for the investor's choice in regression (1), affecting the amount sent; the critical behavior needed to facilitate any efficiency at all. While Investor-T itself is not significant directly in the remaining regressions, it has significant effects through the $\mathrm{S} 1$ and, subsequently, S2 variables. On average investors send about 26 percent more when investors have full transparency, an average of 6.8 in the Investor-Borrower-T and Investor-T treatments versus 5.4 in the No-T and Borrower-T treatments. Interestingly, the prior amounts of the transparent choices, captured by LagS2Vis and LagR3Vis, are not significant in predicting how much of the endowment is put at risk, only the fact the choices were transparent matters. Also the past amounts sent by the investor, LagS1, and returned directly to the investor, LagR3 (which are both always visible to the investor), are predictive.

\footnotetext{
${ }^{10}$ Burnham et al. (2000) did not measure IType; their purpose was simply to compare single play with repeat play using data obtained from subjects in the same session. See Houser's (2003) examination and discussion of types for dynamic decision making.
} 
We observe that the IType coefficient is significant in all of these regressions, confirming the methodological value of our pre-experiment measurement of a person's characteristic willingness to trust. This is important in separating out a source of variation that enables better estimation of treatment and other effects. ${ }^{11}$

Examining the intermediary's sending choice; the direct treatment effects are insignificant in regression (2). The treatment effect is captured by the amount sent by the investor, S1. In all treatments the intermediary sent on average 1.8 times the amount received by the investor except in the No-T treatment where the average was 1.9. Amounts sent and received in the prior period (all visible to the intermediary) also had significant effects. Finally, the intermediary's sending type determined in the one-shot game was predictive.

Similar to regression (2), direct treatment effects are not significant in regression (3) The amount received by the investor (S2) captures all of these effects. The average amount returned was 1.5 times the amount sent by the intermediary in all treatments, except for the No-T treatment, where the average was 1.3. As with the investor, transparency changed what transactions were observable for the borrower across treatments. The additional information given by having S1 transparent to the borrower was insignificant. For lagged variables, only the transactions that directly involved the borrower matter (LagS2 and LagR3). Knowing the transactions between the investor and intermediary (LagS1Vis and LagR2Vis) mattered little. Finally, as in the other cases, the behavior of the borrower in the one-shot game remained predictive.

Finally, we return to the intermediary in regression (4) to examine the amount returned to the investor. The amount sent by the investor, S1, and the amount returned by the borrower, R3,

\footnotetext{
${ }^{11}$ Further, because IType is a constant across all observations from a single player in each regression, it also serves as an effective player fixed effect.
} 
increase the amount returned to the investor, whereas the amount sent to the borrower decreased it. The amount sent by the investor last period, LagS1, and returned by the borrower, LagR3, also are predictive, as is the amount returned by the intermediary last period, LagR2. Again, the intermediary type behavior is significantly affected by her choice in the one-shot game. As with the intermediary's sending decision, the dummy-variables Investor-T and Borrower-T do not load. The treatment effects are captured by S1 and R3 where transparency differs over treatments. The average amount returned to the investor was 0.55 times the amount returned by the borrower in the No-T and Investor-T treatments, increased to 0.57 in the Investor-BorrowerT treatment, but decreased 0.48 in the Borrower-T treatment, where the borrower was not privy to the amount returned to the investor.

In summary, the multivariate results show that:

(1) Players typed as trusting and/or reciprocating in the one-shot setting tend to continue that behavior in the repeated setting. There is also significant persistence in investor and borrower behavior across rounds in the repeated setting.

(2) Investor transparency increases the initial investments and overall efficiency as a result.

(3) More investment creates more lending and more lending creates more return to the intermediary and investor.

(4) History matters in a complex and interesting way. Intermediaries seem to learn through time while all subjects appear affected by how other subjects treated them in the prior period. Specifically, learning through time reduces the willingness of intermediaries to make loans, while good prior returns increases the amounts investors invest.

The history effect creates an interesting, but complex, dynamic relationship. In particular, the coefficients on LagR3 in regressions (2) and (4) suggest that, if borrowers do not pay back 
intermediaries, subsequent loans and returns to investors fall. Then, the coefficient on LagR2 in regression (1) suggests that investors will invest less in subsequent periods. This dynamic would drive down efficiency and economic welfare. On the other hand, higher loan repayment rates would drive the opposite dynamic outcomes. One countervailing force might be increased transparency, but only of a specific kind. Investors knowing the transactions between the intermediary and borrower can improve investment levels.

\section{Discussion and Extensions}

We design an experiment to examine welfare and behavior in a multi-level investment trust game. In the scenario an investor invests via an intermediary who lends to a borrower in a repeated game. We alter the transparency of exchanges between non-adjacent parties. We find that transparency does not change aggregate behavior or efficiency in a one-shot multi-level trust game. However, in repeated multi-level trust games, transparency matters. Providing transparency to the investor (i.e., allowing the investor to see the exchange between the intermediary and the borrower) increases efficiency and payoffs to all players, while providing transparency to the borrower (i.e., allowing the borrower to see the exchange between the investor and intermediary) does not change efficiency and payoffs. Providing transparency to the investor also shifts the distribution of payoffs towards intermediaries and borrowers, while providing transparency to the borrower does not change the distribution of payoffs.

We introduce and test the ability of a one-shot game to measure the trust characteristics of subjects and to predict trusting behavior in a subsequent repeated version of the same stage game. This procedure may have value in other applications not yet explored. 
Overall, our findings indicate that in the multi-level trust game transparency can matter, improving outcomes in financial markets and economic welfare. On the other hand, only one side of transparency matters. For financial markets this implies that not all forms of transparency are equal in their ability to improve market outcomes. In the analog pass through securities market (the collateralized, home mortgage debt obligation market we discussed in the introduction), the ability to verify the credit worthiness of borrowers would seem to be the most important aspect of transparency. In addition, transparency affects welfare asymmetrically. When transparency matters, it is borrowers and intermediaries who benefit more than investors in relative terms. If the policy goal of the government is to make home ownership (and borrowing in general) more accessible, then investor transparency (allowing investors to see the transactions between intermediaries and the ultimate borrowers) can facilitate this while shifting economic welfare toward the ultimate borrowers.

There are several obvious extensions to our research. First, the trust relationship may involve even higher orders and our game would be easy to generalize to three or more levels. Second, trust may be circular instead of linear as we have in our game. It would be simple to design a game where either the borrower gave back money both to the investor and intermediary or, alternatively to the investor with the investor paying the intermediary (as in Sheremeta and Zhang, 2010). Finally, calls for reform often include reporting standards and oversight bodies. One could easily add a monitoring agent to replace direct transparency in our setup up. One could also report prior aggregate outcomes (as in the original Berg, Dickhaut and McCabe, 1995, paper) or current aggregate information. Of course, all may interact with transparency and help us inform policy with respect to transparency, reporting and oversight in financial markets. 


\section{References}

Berg, J., Dickhaut, J., and McCabe., K. 1995, Trust, Reciprocity, and Social History, Games and Economic Behavior 10, 122-142.

Buchner, S., Gonzalez, L.G., Guth, W., and Levati, M.V., 2004, Incentive Contracts versus Trust in Three-player Ultimatum Games: An Experimental Study, European Journal of Political Economy 20, 673-694.

Burnham,.T., K. McCabe and V. Smith, 2000, Friend-or-Foe Intentionality Priming in an Extensive Form Trust Game, Journal of Economic Behavior and Organization 43, 57-73.

Dickhaut, J. McCabe, K., Lunawat, R., Hubbard, J. 2008, Trust, Reciprocity, And Interpersonal History: Fool Me Once, Shame on You, Fool Me Twice, Shame on Me. Working Paper.

Dufwenberg, M., Gneezy, U., Güth, W., Van Demme, E., 2001, Direct versus Indirect Reciprocity: An Experiment, Homo Economicus 18, 19-30.

Fama, E.F., and MacBeth, J.D., 1973, Risk, Return, and Equilibrium: Empirical Tests, Journal of Political Economy 81(3), 607-36.

Greiner, B., and Levati, V.M., 2005, Indirect Reciprocity in Cyclical Networks: An Experimental Study. Journal of Economic Psychology 26, 711-731.

Guth, W., Konigstein, M., Marchand, N., and Nehring, K., 2001, Trust and Reciprocity in the Investment Game with Indirect Reward, Homo Economicus 18, 241-262.

Houser, D., 2003, Classification of Types for Dynamic Decision Makers, In L. Nadel, ed. Encyclopedia of Cognitive Science, vol. 1, 1020-1026 (London: Nature Publishing Group).

Nowak, M.A., and Sigmund, K., 1998, The Dynamics of Indirect Reciprocity, Journal of Theoretical Biology 194, 561-574.

Obama, B., 2010, Letter to G-20, June 16, 2010, Accessed on 9/30/2010 at: http://www.whitehouse.gov/sites/default/files/rss_viewer/president_obama_letter_to_g20_061610.pdf

Rapoport, A., Stein, W. E., Parco, J. E., and Nicholas, T. E., 2003, Equilibrium Play and Adaptive Learning in a Three-player Centipede Game, Games and Economic Behavior 43, 239-65.

Rigdon, M., K. McCabe and V. Smith, 2007, Sustaining Cooperation in Trust Games, Economic Journal 117, 991-1007.

Seinen, I., and Schram, A., 2006, Social Status and Group Norms: Indirect Reciprocity in a Repeated Helping Experiment, European Economic Review 50, 581-602.

Sheremeta, R.M., \& Zhang, J. 2010, Multi-Level Trust Game with "Insider” Communication, McMaster University, Working Paper.

Wedekind, C., and Milinski, M., 2000, Cooperation Through Image Scoring in Humans, Science $288,850-852$.

Wichman, H., 1972, Effects of Isolation and Communication on Cooperation in a Two-player Game, In L. S. Wrightsman, J. O'Connor, and N. J. Baker (Eds.), Cooperation and Competition: Readings on Mixed-Motive Games, 197-206. (Belmont, CA: Brooks/Cole Publishing Company). 


\section{Tables and Figures}

Table 1: Summary of Treatments

\begin{tabular}{|c|c|c|c|}
\hline Treatment & $\begin{array}{l}\text { Players Observing } \\
\text { Additional Information }\end{array}$ & $\begin{array}{l}\text { Transparency About } \\
\text { Transactions of: }\end{array}$ & $\begin{array}{l}\text { Number } \\
\text { of Subjects }\end{array}$ \\
\hline No-T & None & None & 48 \\
\hline Borrower- $T$ & Borrower & Investor and Intermediary & 48 \\
\hline Investor-T & Investor & Intermediary and Borrower & 48 \\
\hline Investor-Borrower- $\mathrm{T}$ & Investor and Borrower & All Players & 48 \\
\hline
\end{tabular}

Table 2: Average Statistics by Treatment

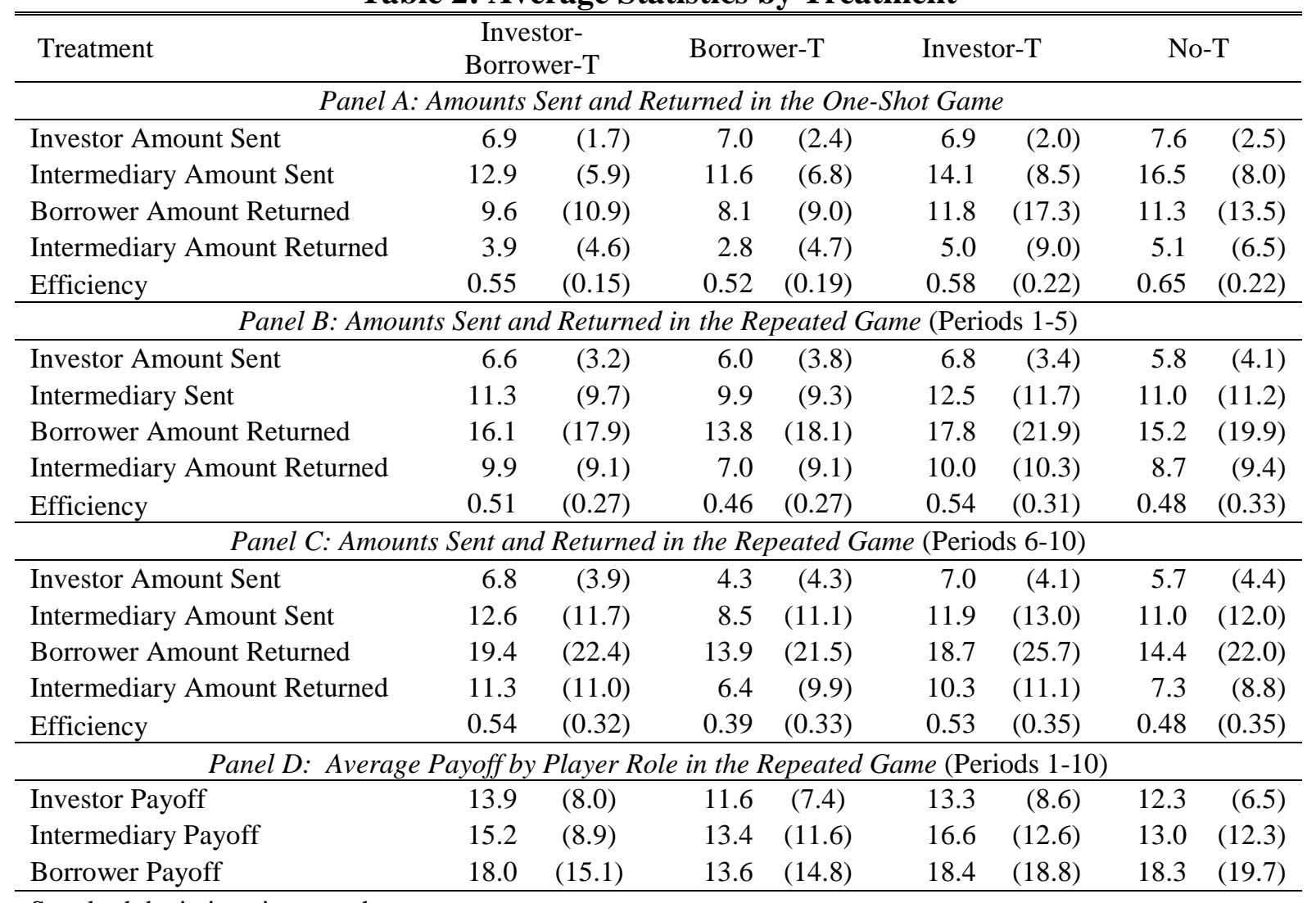

Standard deviations in parentheses 
Table 3: Efficiency, Payoffs and Distribution of Payoffs in the One-Shot Game

\begin{tabular}{lccccccc}
\hline \hline Regression & $(1)$ & $(2)$ & $(3)$ & $(4)$ & $(5)$ & \multicolumn{3}{c}{ Share of Payoff to } \\
\hline \multirow{2}{*}{ Variables } & Efficiency & \multicolumn{3}{c}{ Payoff to } & \multicolumn{4}{c}{$(7)$} \\
\cline { 2 - 7 } & Investor & Intermediary & Borrower & Investor & Intermediary & Borrower \\
\hline Investor-T & -0.023 & 0.937 & -0.250 & -2.562 & 0.020 & 0.000 & -0.020 \\
& $(0.055)$ & $(1.367)$ & $(2.167)$ & $(4.071)$ & $(0.024)$ & $(0.045)$ & $(0.050)$ \\
Borrower-T & -0.086 & -1.375 & 1.062 & -6.562 & -0.002 & 0.062 & -0.060 \\
& $(0.055)$ & $(1.367)$ & $(2.167)$ & $(4.071)$ & $(0.024)$ & $(0.045)$ & $(0.050)$ \\
Constant & $0.577 * * *$ & $7.281 * * *$ & $13.188 * * *$ & $35.656 * *$ & $0.137 * *$ & $0.252^{* * *}$ & $0.612 * * *$ \\
& $(0.048)$ & $(1.184)$ & $(1.877)$ & $(3.526)$ & $(0.021)$ & $(0.039)$ & $(0.043)$ \\
\hline Observations & 64 & 64 & 64 & 64 & 64 & 64 & 64 \\
R-squared & 0.041 & 0.023 & 0.004 & 0.045 & 0.011 & 0.031 & 0.026 \\
\hline
\end{tabular}

$* * * \mathrm{p}<0.01, * * \mathrm{p}<0.05, * \mathrm{p}<0.1$.

Robust standard errors in parentheses. Regressions (2)-(4) and (5)-(7) are estimated using simultaneous equation estimation procedures to control for endogeneity.

Table 4: Regression of Amounts Sent and Returned in the One-Shot Game

\begin{tabular}{lcccc}
\hline \hline Regression & $(1)$ & $(2)$ & $(3)$ & $(4)$ \\
\hline Variables & $\mathrm{S} 1$ & $\mathrm{~S} 2$ & $\mathrm{R} 3$ & $\mathrm{R} 2$ \\
\hline Investor-T & -0.406 & -0.531 & 0.969 & 0.531 \\
& $(0.536)$ & $(1.807)$ & $(3.169)$ & $(1.565)$ \\
Borrower-T & -0.344 & $-3.094 *$ & -2.719 & -1.719 \\
& $(0.536)$ & $(1.807)$ & $(3.169)$ & $(1.565)$ \\
Constant & $7.484 * * *$ & $15.578 * * *$ & $11.078 * * *$ & $4.766 * * *$ \\
& $(0.464)$ & $(1.565)$ & $(2.744)$ & $(1.356)$ \\
\hline Observations & 64 & 64 & 64 & 64 \\
R-squared & 0.015 & 0.045 & 0.013 & 0.020 \\
\hline$* * * \mathrm{p}<0.01, * * \mathrm{p}<0.05, * \mathrm{p}<0.1$. & & &
\end{tabular}

Robust standard errors in parentheses. Regressions (1)-(4) are estimated using simultaneous equation estimation procedures to control for endogeneity.

Table 5: Efficiency, Payoffs and Distribution of Payoffs in the Repeated Game

\begin{tabular}{|c|c|c|c|c|c|c|c|}
\hline Regression & $(1)$ & $(2)$ & (3) & (4) & (5) & $(6)$ & (7) \\
\hline \multirow[b]{2}{*}{ Variables } & \multirow[b]{2}{*}{ Efficiency } & \multicolumn{3}{|c|}{ Payoff to } & \multicolumn{3}{|c|}{ Share of Payoff to } \\
\hline & & Investor & Intermediary & Borrower & Investor & Intermediary & Borrower \\
\hline \multirow[t]{2}{*}{ Investor-T } & $0.086 * * *$ & $1.690 * * *$ & $2.723 * * *$ & $2.435 *$ & $-0.093 * * *$ & $0.063 * * *$ & $0.030 *$ \\
\hline & $(0.028)$ & $(0.605)$ & $(0.901)$ & $(1.358)$ & $(0.024)$ & $(0.015)$ & $(0.018)$ \\
\hline \multirow[t]{2}{*}{ Borrower- $\mathrm{T}$} & -0.027 & -0.040 & -0.395 & -1.975 & -0.005 & 0.012 & -0.007 \\
\hline & $(0.029)$ & $(0.607)$ & $(0.902)$ & $(1.376)$ & $(0.024)$ & $(0.015)$ & $(0.018)$ \\
\hline \multirow[t]{2}{*}{ Inverse Period } & 0.095 & $-4.342 *$ & -0.388 & $12.301 * *$ & $-0.501 * * *$ & $0.123^{*}$ & $0.378 * * *$ \\
\hline & $(0.115)$ & $(2.463)$ & $(3.677)$ & $(5.527)$ & $(0.098)$ & $(0.063)$ & $(0.072)$ \\
\hline \multirow[t]{2}{*}{ Constant } & $0.314 * * *$ & $12.910 * * *$ & $14.423 * * *$ & $11.805 * * *$ & $0.573 * * *$ & $0.232 * * *$ & $0.195 * * *$ \\
\hline & $(0.050)$ & $(0.803)$ & $(1.216)$ & $(2.101)$ & $(0.029)$ & $(0.018)$ & $(0.021)$ \\
\hline Observations & 640 & 640 & 640 & 640 & 640 & 640 & 640 \\
\hline R-squared & 0.023 & 0.017 & 0.021 & 0.024 & 0.060 & 0.032 & 0.046 \\
\hline
\end{tabular}

$* * * \mathrm{p}<0.01, * * \mathrm{p}<0.05, * \mathrm{p}<0.1$.

Robust standard errors in parentheses. Regressions (2)-(4) and (5)-(7) are estimated using simultaneous equation estimation procedures to control for endogeneity. 
Table 6: Regression of Amounts Sent and Returned in the Repeated Game

\begin{tabular}{|c|c|c|c|c|}
\hline Regression & (1) & (2) & (3) & (4) \\
\hline Variables & S1 & S2 & R3 & R2 \\
\hline Inverse Period & $\begin{array}{c}2.574 \\
(1.630)\end{array}$ & $\begin{array}{l}7.129 * * \\
(3.236)\end{array}$ & $\begin{array}{c}7.295 \\
(4.668)\end{array}$ & $\begin{array}{l}3.490^{*} \\
(1.969)\end{array}$ \\
\hline Investor- $\mathrm{T}$ & $\begin{array}{c}0.928 * * * \\
(0.323)\end{array}$ & $\begin{array}{l}-0.207 \\
(0.493)\end{array}$ & $\begin{array}{c}0.460 \\
(0.699)\end{array}$ & $\begin{array}{c}0.363 \\
(0.298)\end{array}$ \\
\hline Borrower- $\mathrm{T}$ & $\begin{array}{l}-0.145 \\
(0.245)\end{array}$ & $\begin{array}{c}-0.108 \\
(0.493)\end{array}$ & $\begin{array}{c}1.601 \\
(1.186)\end{array}$ & $\begin{array}{c}0.284 \\
(0.294)\end{array}$ \\
\hline IType & $\begin{array}{c}0.124 * * \\
(0.060)\end{array}$ & $\begin{array}{c}0.112 * * * \\
(0.034)\end{array}$ & $\begin{array}{r}0.075^{* *} \\
(0.029)\end{array}$ & $\begin{array}{c}0.083 * * * \\
(0.024)\end{array}$ \\
\hline \multicolumn{5}{|c|}{ Current Period's Observable Choices } \\
\hline S1 & & $\begin{array}{c}1.419 * * * \\
(0.082)\end{array}$ & & $\begin{array}{c}0.826^{* * * *} \\
(0.061)\end{array}$ \\
\hline $\mathrm{S} 2$ & & & $\begin{array}{c}1.331 * * * \\
(0.053)\end{array}$ & $\begin{array}{c}-0.327 * * * \\
(0.036)\end{array}$ \\
\hline R3 & & & & $\begin{array}{c}0.451 * * * \\
(0.018)\end{array}$ \\
\hline \multirow[t]{2}{*}{ S1Vis } & & & $\begin{array}{l}-0.019 \\
(0.192)\end{array}$ & \\
\hline & Prior Per & Observable & & \\
\hline LagS1 & $\begin{array}{c}0.354 * * * \\
(0.052)\end{array}$ & $\begin{array}{c}-0.310 * * \\
(0.122)\end{array}$ & & $\begin{array}{c}-0.431 * * * \\
(0.074)\end{array}$ \\
\hline LagS2 & & $\begin{array}{c}-0.174 * * \\
(0.069)\end{array}$ & $\begin{array}{c}-0.289 * * * \\
(0.082)\end{array}$ & $\begin{array}{c}0.181 * * * \\
(0.042)\end{array}$ \\
\hline LagR3 & & $\begin{array}{c}0.456 * * * \\
(0.045)\end{array}$ & $\begin{array}{c}0.393 * * * \\
(0.051)\end{array}$ & $\begin{array}{c}-0.272 * * * \\
(0.030)\end{array}$ \\
\hline LagR2 & $\begin{array}{c}0.160 * * * \\
(0.023)\end{array}$ & $\begin{array}{c}-0.147 * * \\
(0.073)\end{array}$ & & $\begin{array}{c}0.589 * * * \\
(0.044)\end{array}$ \\
\hline LagS1Vis & & & $\begin{array}{l}-0.284 \\
(0.213)\end{array}$ & \\
\hline LagS2Vis & $\begin{array}{l}-0.025 \\
(0.041)\end{array}$ & & & \\
\hline LagR3Vis & $\begin{array}{c}0.004 \\
(0.024)\end{array}$ & & & \\
\hline LagR2Vis & & & $\begin{array}{c}0.107 \\
(0.090)\end{array}$ & \\
\hline Constant & $\begin{array}{c}0.748 \\
(0.560) \\
\end{array}$ & $\begin{array}{c}-2.529 * * * \\
(0.945) \\
\end{array}$ & $\begin{array}{c}-4.054 * * * \\
(1.096) \\
\end{array}$ & $\begin{array}{c}-1.362 * * * \\
(0.485) \\
\end{array}$ \\
\hline Observations & 576 & 576 & 576 & 576 \\
\hline R-squared & 0.483 & 0.750 & 0.859 & 0.884 \\
\hline
\end{tabular}

$* * * \mathrm{p}<0.01, * * \mathrm{p}<0.05, * \mathrm{p}<0.1$.

Robust standard errors in parentheses. Regressions (1)-(4) are estimated using simultaneous equation estimation procedures to control for endogeneity. 


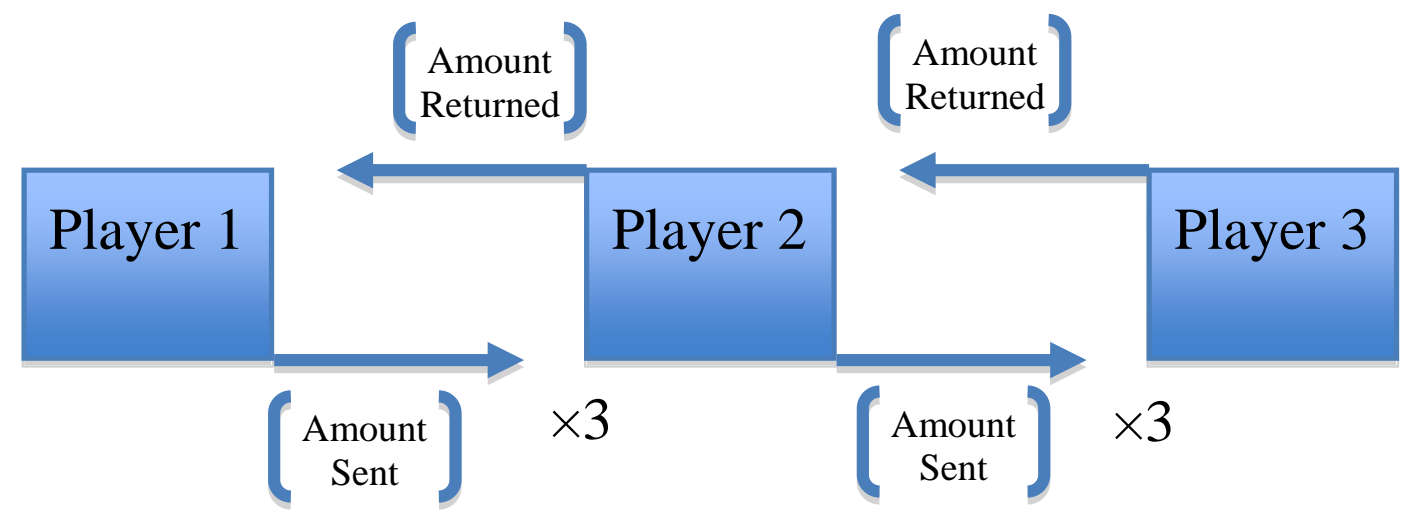

Figure 1: Three-Player Trust Game Screen Shot from the Experiment

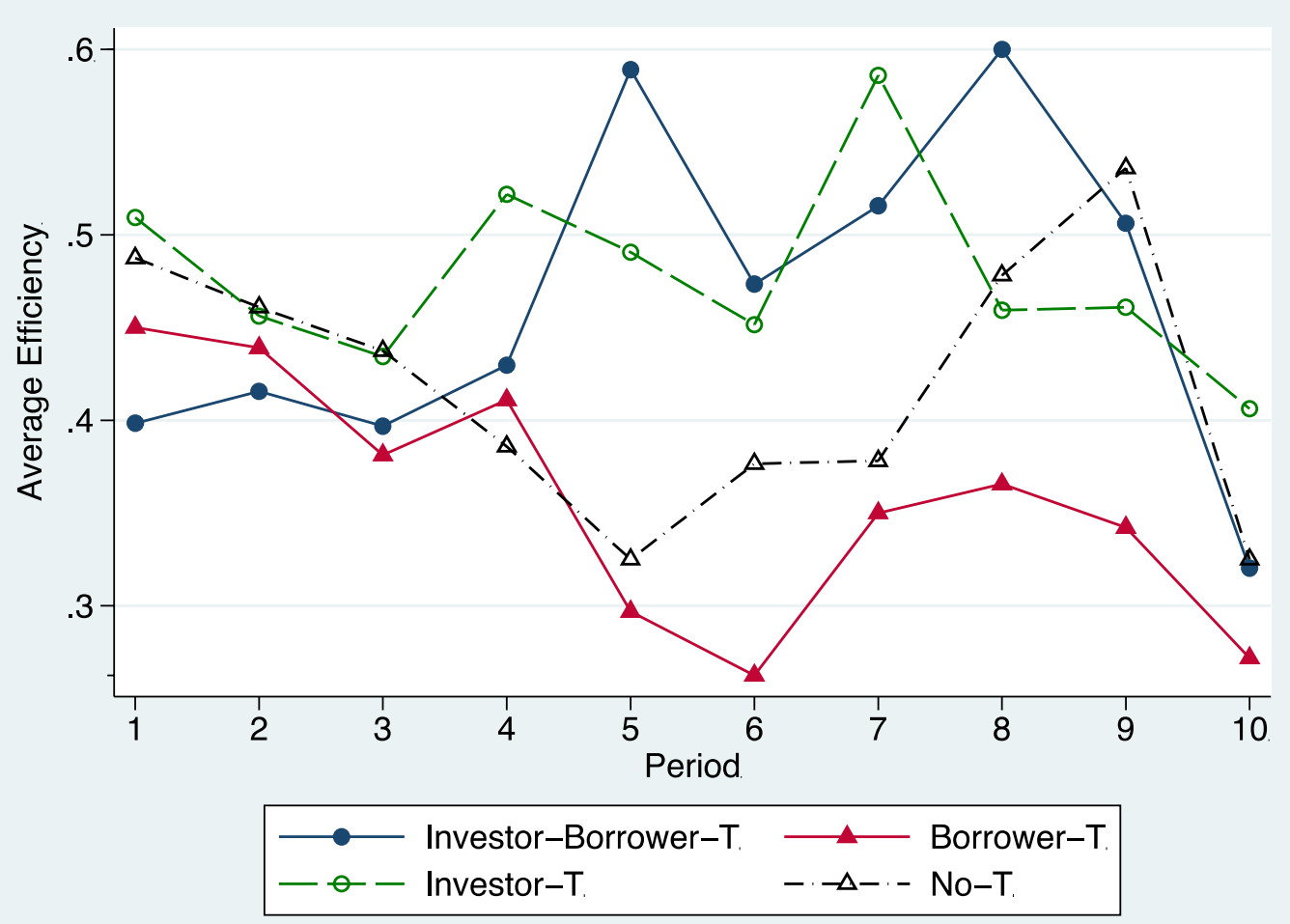

Figure 2: Time Series of Efficiency in the Repeated Game 


\section{Supplementary Appendix}

\section{INSTRUCTIONS (Example of the No-Transparency Treatment)}

This is an experiment in the economics of decision-making. Various research agencies have provided funds for this research. The currency used in the experiment is experimental dollars, and they will be converted to U.S. Dollars at a rate of __ experimental dollars to _ 1 _ dollar. At the end of experiment your earnings will be paid to you in private and in cash. It is very important that you remain silent and do not look at other people's work. If you have any questions, or need assistance of any kind, please raise your hand and an experimenter will come to you. If you talk, laugh, exclaim out loud, etc., you will be asked to leave and you will not be paid. We expect and appreciate your cooperation.

The 24 participants in today's experiment will be randomly assigned into 8 three-player groups. In addition to the group assignment each participant will also be randomly assigned to a specific type in the group, designated as Player 1, Player 2, or Player 3. You and the other two participants in your group will make choices that will determine your payoffs. The experiment consists of four decision stages.

In stage 1, Player 1 receives $\$ 10$ and then decides how many dollars to send to Player 2. The amount sent by Player 1 is multiplied by 3 . In stage 2, Player 2 decides how many dollars to send to Player 3. The amount sent by Player 2 is multiplied by 3. In stage 3, Player 3 decides how many dollars to send back to Player 2 . Finally, in stage 4, Player 2 decides how many dollars to 
send back to Player 1. Not all amounts are visible to all Players as shown in the following diagram:

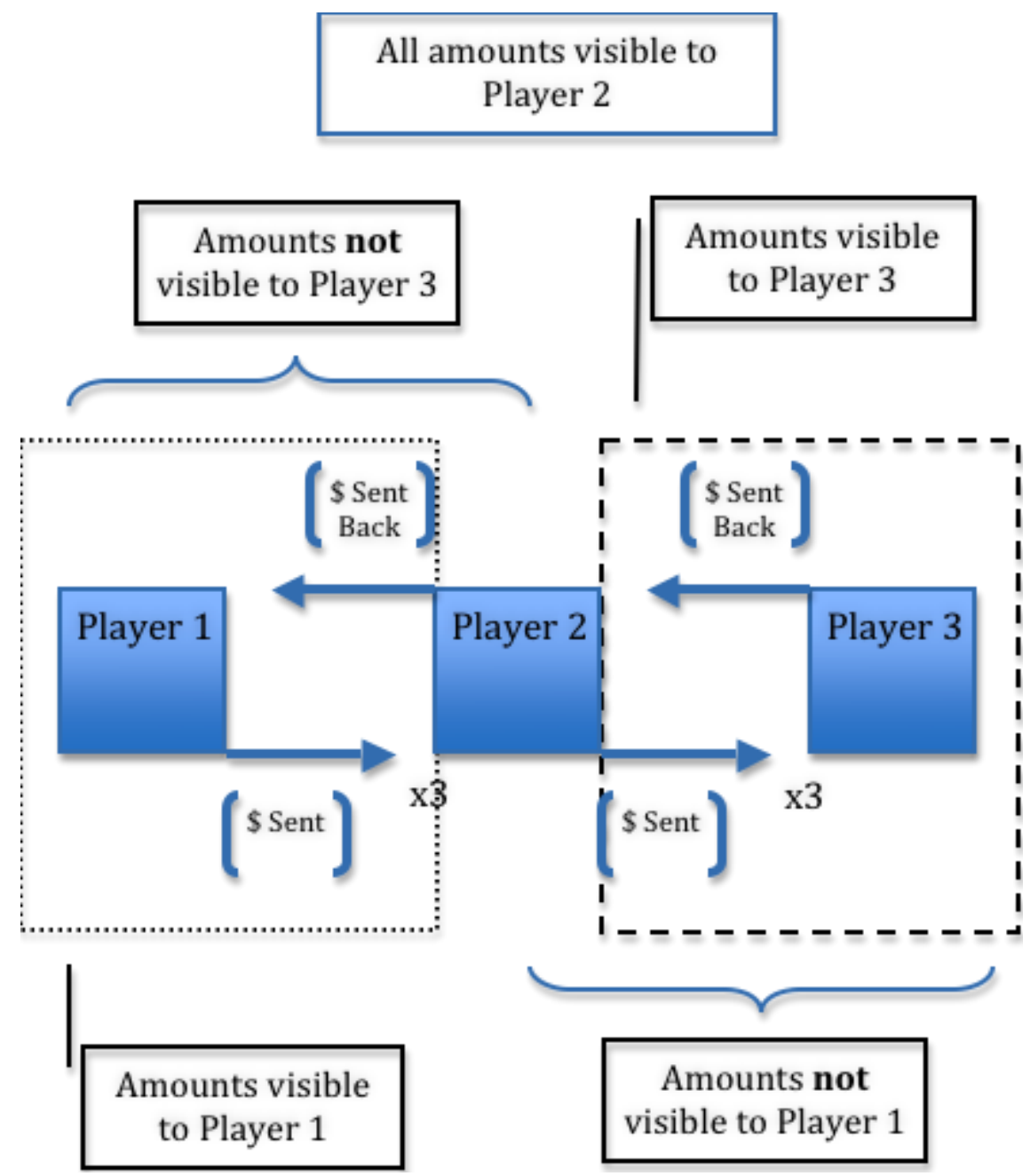

Next we describe in details the decisions made by all players in each stage of the experiment.

Stage 1: Player 1 receives $\$ 10$ and then decides how many dollars to send to Player 2 (any integer between 0 and 10). Player 1 enters the amount sent to Player 2 in the box labeled "The amount sent by Player 1" below. The amount sent by Player 1 is multiplied by 3 . Any amount that is not sent is automatically allocated to Player 1's account. 
After making this decision, Player 1 will only learn the decision made Player 2 in stage 4. However, Player 1 will not learn the decisions made by Player 2 in stage 2 and Player 3 in stage 3.

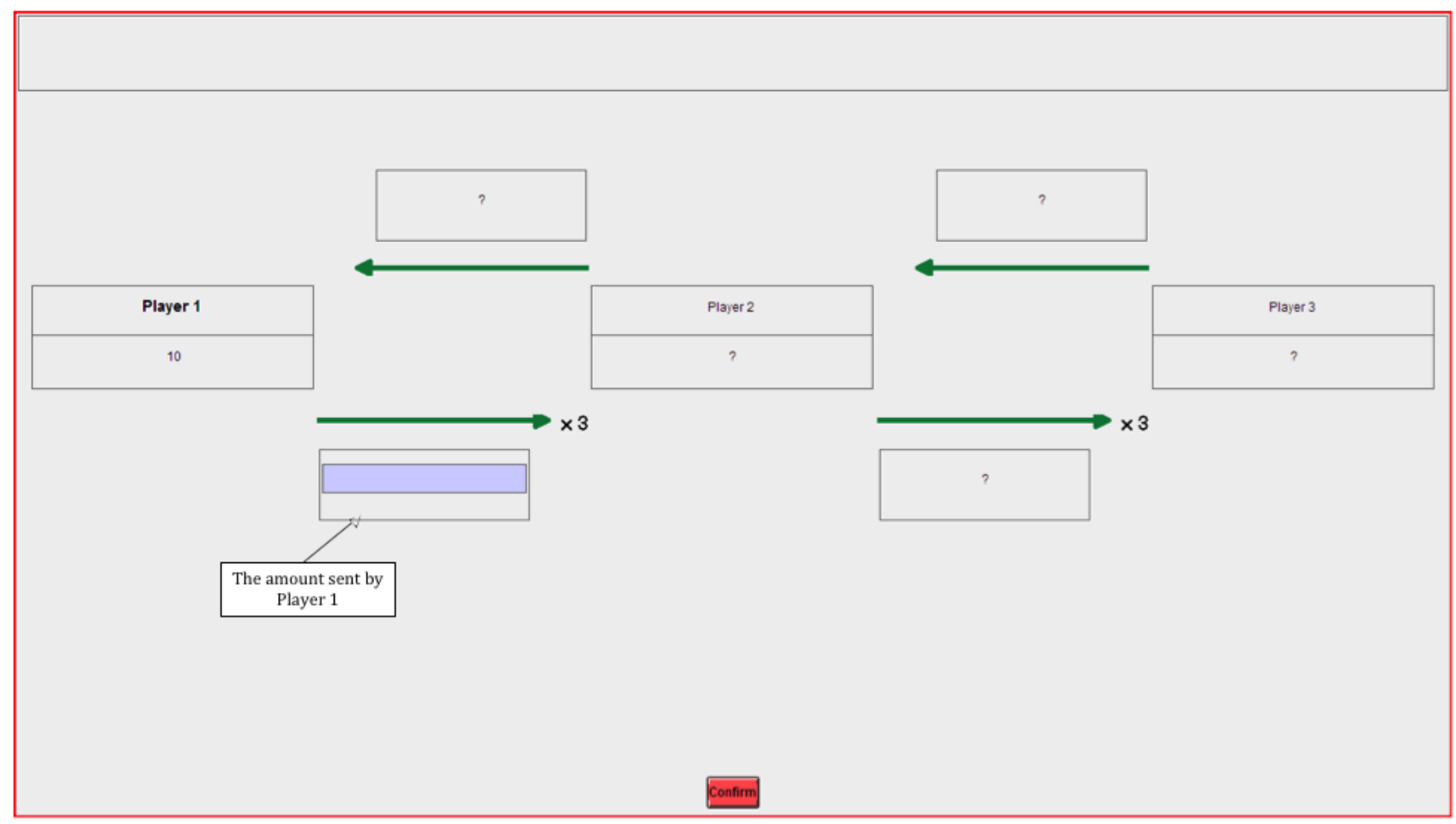

Decision Screen for Player 1 in Stage 1

Stage 2: After learning the amount sent by Player 1 in stage 1, Player 2 decides how many dollars to send to Player 3 (any integer between 0 and the amount available in Player 2's account at that time). Player 2 enters the amount sent to Player 3 in the box labeled "The amount sent by Player 2" below. The amount sent by Player 2 is multiplied by 3 . Any amount that is not sent is automatically allocated to Player 2's account. 
Player 2 will learn all the decisions made by all players in all stages.

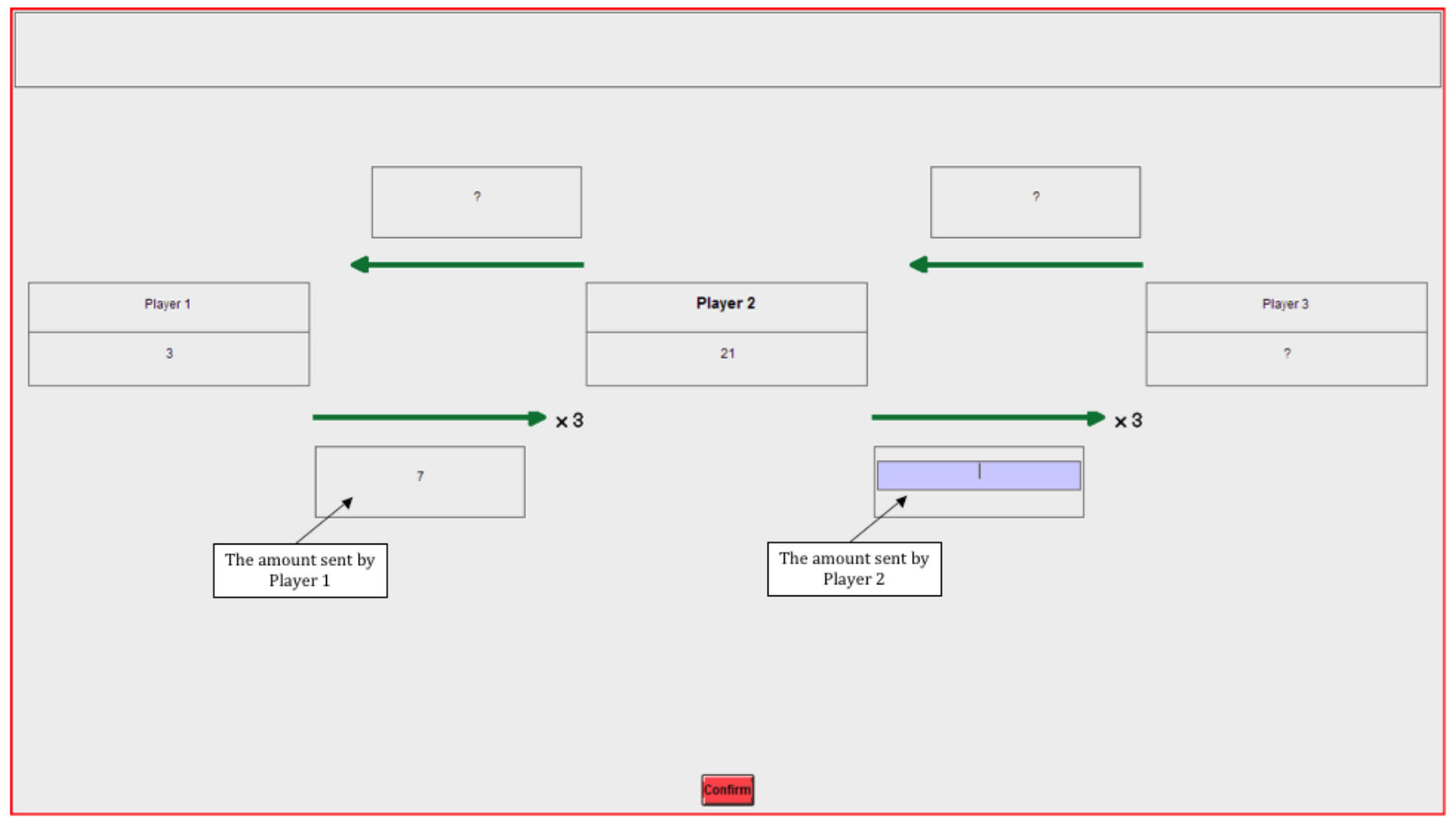

Decision Screen for Player 2 in Stage 2

Stage 3: After learning the amount sent by Player 2 in stage 2, Player 3 decides how many dollars to send back to Player 2 (any integer between 0 and the amount available in Player 3's account at that time). Player 3 enters the amount sent back to Player 2 in the box labeled "The amount sent back by Player 3" below. The amount send back by Player 3 is NOT multiplied. Any amount that is not sent is automatically allocated to Player 3's account.

Before making this decision, Player 3 will only learn the decision made by Player 2 in stage 2 . However, Player 3 will not learn the decisions made by Player 1 in stage 1 and Player 2 in stage 4. 


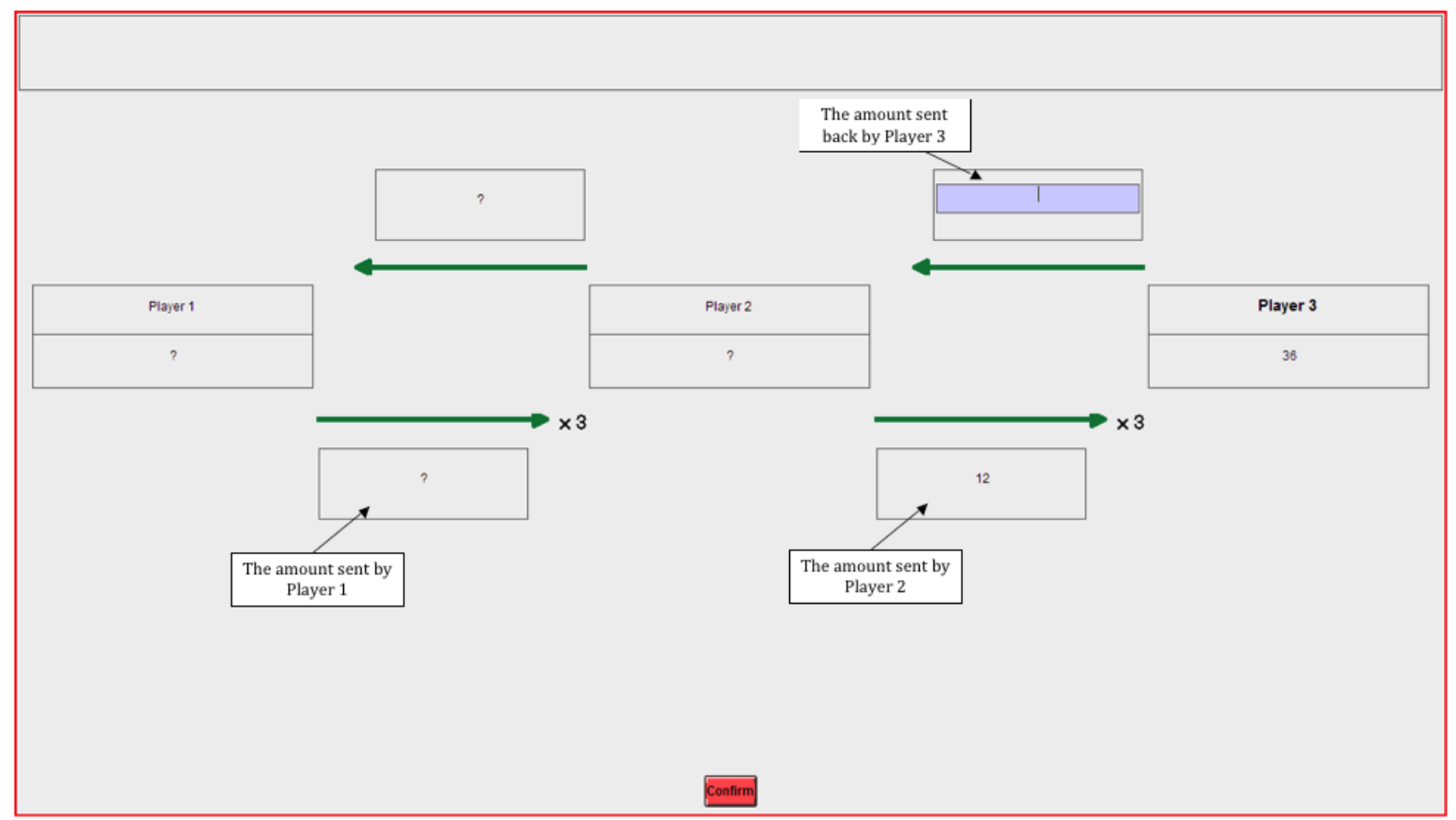

Decision Screen for Player 3 in Stage 3

Stage 4: After learning the amount sent back by Player 3 in stage 3, Player 2 decides how many dollars to send back to Player 1 (any integer between 0 and the amount available in Player 2's account at that time). Player 2 enters the amount sent back to Player 1 in the box labeled "The amount sent back by Player 2" below. The amount send back by Player 2 is NOT multiplied. Any amount that is not sent is automatically allocated to Player 2's account. 


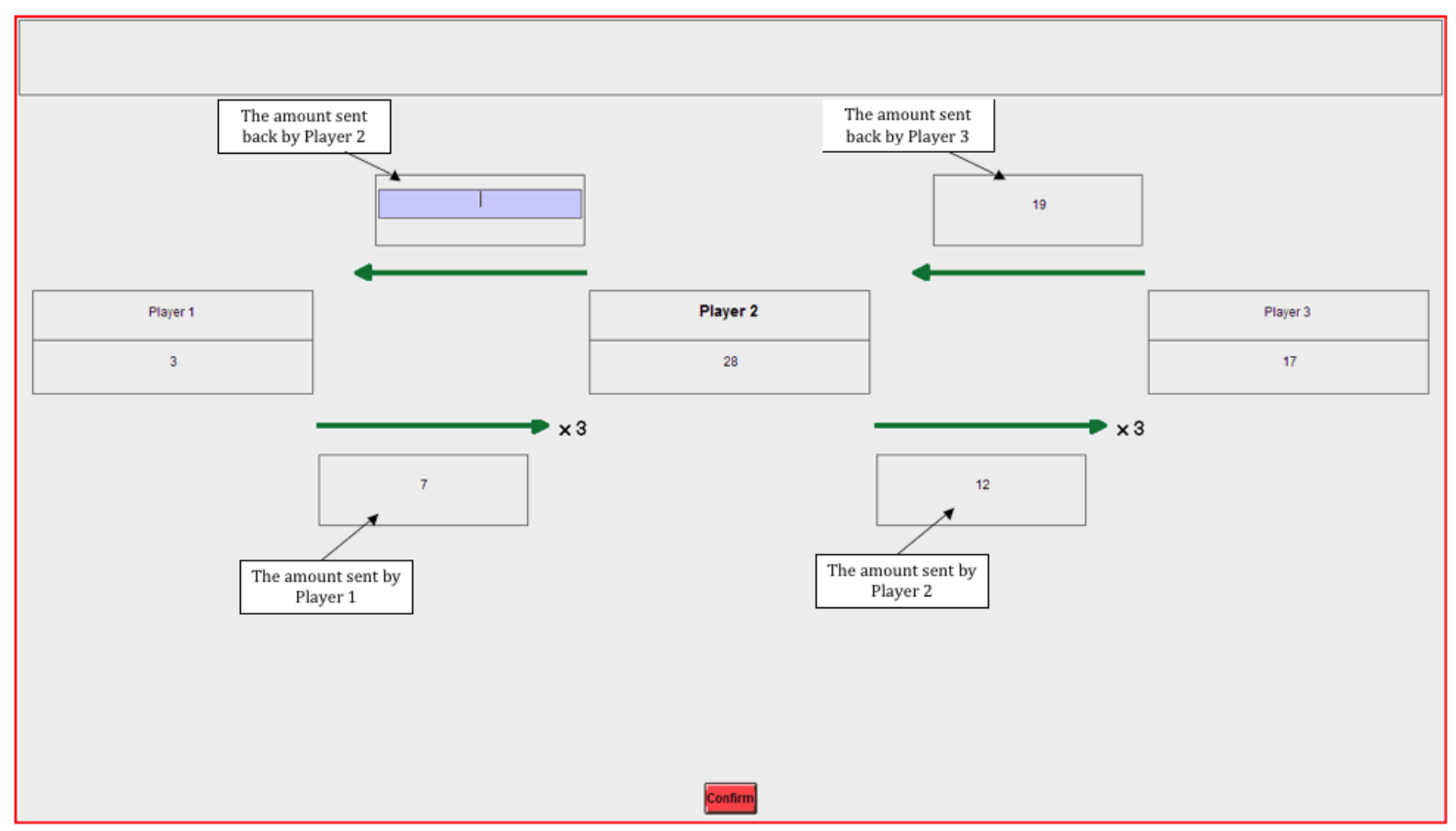

Decision Screen for Player 2 in Stage 4

Finally, at the end of the Stage 4 the total earnings are reported to each person. Please record the decisions and your earnings on your record sheet under the appropriate heading.

\section{SUMMARY}

The computer will assign you and two other participants to a three-player group, consisting of Player 1, Player 2, and Player 3. In stage 1, Player 1 receives $\$ 10$ and then decides how many dollars to send to Player 2. The amount sent by Player 1 is multiplied by 3 . In stage 2, Player 2 decides how many dollars to send to Player 3. The amount sent by Player 2 is multiplied by 3 . In stage 3, Player 3 decides how many dollars to send back to Player 2. Finally, in stage 4, Player 2 decides how many dollars to send back to Player 1. 
After making the first decision, Player 1 will only learn the decision made Player 2 in stage 4. However, Player 1 will not learn the decisions made by Player 2 in stage 2 and Player 3 in stage 3. Player 2 will learn all the decisions made by all players in all stages. Before making a decision, Player 3 will only learn the decision made by Player 2 in stage 2 . However, Player 3 will not learn the decisions made by Player 1 in stage 1 and Player 2 in stage 4.

At the end of Stage 4 the total earnings are reported to each person. This experiment is now over and your earnings will be part of the total you will be paid.

\section{EXAMPLE}

Consider a hypothetical example:

Stage 1: Player 1 sends $\$ 7$ to Player 2

Stage 2: Player 2 sends $\$ 12$ to Player 3

Stage 3: Player 3 sends back $\$ 19$ to Player 2

Stage 4: Player 2 sends back $\$ 16$ to Player 1

In stage 1, Player 1 sends $\$ 7$ to Player 2 and keeps $\$ 3(\$ 10-\$ 7=\$ 3)$. The amount received by Player 2 is $\$ 21(\$ 7 \times 3=\$ 21)$. At the end of stage 1, Player 2 learns the decision made by Player 1 .

In stage 2, Player 2 sends $\$ 12$ to Player 3 and keeps $\$ 9(\$ 21-\$ 12=\$ 9)$. The amount received by Player 3 is $\$ 36(\$ 12 \times 3=\$ 36)$. At the end of stage 2, Player 3 learns the decision made by Player 2. 
In stage 3, Player 3 sends back $\$ 19$ to Player 2 and keeps $\$ 17$ (\$36-\$19=\$17). The amount received by Player 2 is $\$ 19$. However, Player 2 also has an additional $\$ 9$ which was kept in stage 2 , for a total of $\$ 28(\$ 19+\$ 9=\$ 28)$. At the end of stage 3, Player 2 learns the decision made by Player 3.

In stage 4, Player 2 sends back $\$ 16$ to Player 1 and keeps $\$ 12$ (\$28-\$16=\$12). However, Player 1 also has an additional $\$ 3$ which was kept in stage 1 , for a total of $\$ 19(\$ 16+\$ 3=\$ 19)$. At the end of stage 4, Player 1 learns the decision made by Player 2.

As the result, the total earnings for each player are:

Player 1 earns $\$ 19$

Player 2 earns $\$ 12$

Player 3 earns $\$ 17$

QUIZ \#1

A hypothetical example:

Stage 1: Player 1 sends $\$ 2$ to Player 2

Stage 2: Player 2 sends $\$ 0$ to Player 3

Stage 3: Player 3 sends back $\$ 0$ to Player 2

Stage 4: Player 2 sends back $\$ 0$ to Player 1

What are the total earnings for each player?

Player 1 earns ? 
Player 2 earns

- $?$

Player 3 earns

QUIZ \#2

A hypothetical example:

Stage 1: Player 1 sends $\$ 9$ to Player 2

Stage 2: Player 2 sends $\$ 25$ to Player 3

Stage 3: Player 3 sends back $\$ 50$ to Player 2

Stage 4: Player 2 sends back $\$ 15$ to Player 1

What are the total earnings for each player?

Player 1 earns ___ ?

Player 2 earns ___ ?

Player 3 earns ___ ?

(The following distributed after subjects played the one-shot game)

INSTRUCTIONS - 10 MORE REPLICATIONS

This experiment consists of 10 decision-making periods. The rules for each period are exactly the same as the rules for the previous experiment. In all 10 periods of the experiment you will remain the same type of player as in the previous experiment. However, at the beginning of the first period, you will be randomly rematched with two other players of the other types to form a new three-player group. You will remain with this new three-player group for all 10 periods of the experiment. 
During each period, you and the other two participants in your group will make choices as in the previous experiment that will determine your payoffs. Please record the decisions and your earnings in each period on your record sheet under the appropriate heading.

We will randomly choose 1 of the 10 periods for actual payment using a die roll using a tensided die with numbers from 1 to 10 . Your final earnings for these experiments consist of: (1) your show up fee, (2) earnings from the first experiment and (3) you earnings from the randomly selected period in the second experiment. Note that after this 10-period experiment there will be no further experiments and your earnings will be paid to you in private and in cash. 